\title{
Аминокислоты в условиях ионизации при электрораспылении: использование хлорида никеля для инициирования кластерообразования
}

\author{
Кузнецова Е.С., Пыцкий И.С., Буряк А.К. \\ Федеральное Государственное Бюджетное Учреждение Науки Институт физической химии \\ и электрохимии им. А.Н. Фрумкина РАН, Москва
}

Поступила в редакцию 19.09.2018 г.

DOI: https://doi.org/10.17308/sorpchrom.2018.18/613

\begin{abstract}
Проведено систематическое исследование ионизации аминокислот методом ионизации электрораспылением (ESI-MS) в присутствии хлорида никеля. Проведено исследование влияния состава подвижной фазы на качество и состав масс-спектров. Состав смеси ацетонитрил-вода варьировался от 5 до 95\% воды. Установлено, что изменение состава подвижной фазы существенно оказывает некоторое влияние на интенсивность масс-спектров, но не на качественный состав. Качество масс-спектра значительно зависит от чистоты используемого ацетонитрила, который в больших количествах увеличивает химический шум и затрудняет идентификацию. Наилучшим для работы соотношением было 45\% воды и 55\% ацетонитрила. Показано, что для ароматических аминокислот (тирозина, триптофана) наиболее характерны как процессы фрагментации (декарбоксилирование, деаминирование, распад по $\alpha$-углероду), так и в некоторой степени и процессы кластерообразования с участием атомов никеля. Также показано, что наиболее интенсивно кластерообразование проходит в простых неароматических аминокислотах. Видно, что кластерообразование в таких случаях идёт по трём различным направлениям: образование молекулярных ассоциатов аминокислот с несущим заряд протоном, образование молекулярных ассоциатов аминокислот с несущим заряд атомом никеля и образование полимолекулярных координированных структур, координируемых двумя ионами никеля. В работе показано, что результаты полученные при исследовании могут быть использованы не только для более чувствительного и информативного поиска аминокислот в растворах сложных смесей с хроматографическим разделением и при использовании прямого ввода, но для более надёжной идентификации целевых соединений благодаря образованию кластеров целевых соединений (в случае неароматических соединений) и характерной фрагментации (в случае ароматических соединений).
\end{abstract}

Ключевые слова: масс-спектрометрия, сульфат меди, кластерообразование, аминокислоты, ионизация электрораспылением, катионирование, ионные кластеры.

\section{Amino acids under ionization conditions during electrospraying: use of nickel chloride to initiate cluster formation}

\author{
Kuznetsova E.S., Pytskii I.S., Buryak A.K. \\ Institute of Physical Chemistry and Electrocemistry RAS (IPCE RAS), Moscow
}

A systematic study of the ionization of amino acids by the method of electrospray ionization (ESIMS) in the presence of nickel chloride was carried out. The influence of the mobile phase on the quality and composition of the mass spectra was studied. The composition of the acetonitrile-water mixture varied from 5 to $95 \%$ water. It was found that the change in the constituent part of the mass spectra, but not in the qualitative composition. The quality of mass spectra depends significantly on the purity of the acetonitrile used,

$\boldsymbol{K}$ узнецова и др. / Сорбционные и хроматографические процессы. 2018. Т. 18. № 6 
which in large quantities increases chemical noise and makes identification difficult. The best ratio for work was $45 \%$ water and $55 \%$ acetonitrile. It has been shown that for aromatic amino acids (tyrosine, tryptophan) the most typical processes are both fragmentation (decarboxylation, deamination, decay in $\alpha$-carbon) and, to some extent, cluster formation processes involving nickel atoms. It has also been shown that claster formation occurs most intensively in simple non-aromatic amino acids. It can be seen that cluster formation in such cases proceeds in three different directions: the formation of molecular associates of amino acids with a charge carrying a proton, the formation of molecular associates of amino acids with a charge-carrying nickel atom, and the formation of polymolecular coordinated structures coordinated by two nickel ions.

It is shown that the results obtained in the study can be used not only for a more sensitive and informative search for amino acids in solutions of complex mixtures with chromatographic separation and using direct input, but for more reliable identification of the target compounds due to the formation of clusters of the target compounds (in the case of non-aromatic compounds) and characteristic fragmentation (in the case of aromatic compounds). This study will be useful not only to expand the field of physico-chemical knowledge, but also to improve the methods of applied research.

Keywords: mass spectrometry, copper sulfate, clustering, amino acids, electrospray ionization, cationization, ion clusters

\section{Введение}

Одним из наиболее популярных областей исследования современной физикохимии является изучения процессов происходящих при ионизации в различных условиях [1-2]. Одним из популярных методов подобных исследований является матрично-активированная лазерная десорбция/ионизация (МАЛДИ). Наиболее полно эти процессы описаны в [3]. Указанный метод является разновидностью фотоионизации в вакууме с различных поверхностей. Наиболее часто этот метод применяется при исследовании макромолекул (белков, пептидов, искусственных полимеров) [4]. Также широко известен факт образования крупных кластерных ионов при использовании этого метода. В частности подобные исследования проводились и авторами настоящей работы[5,6]. Альтернативным методом исследования кластерообразования является метод электрораспыления ESI-MS. Этот метод является также «мягким», но в отличие от МАЛДИ ионизация в нём производится не с поверхности, а из объёма микрокапель находящихся в поле высокой напряжённости. При распылении капель в статическом электрическом поле с последующей сушкой летящих капель через перпендикулярный поток сухого азота, капли уменьшаются в размерах, вызывая агломерацию заряженных частиц и последующий кулоновский взрыв с образованием крупных одно- и полизаряженных капель. Процесс заряжения можно контролировать подбором параметров эксперимента. Процессы зарядки и агломерации органических молекул подробно описаны в [7]. В настоящей работе метод ESI-MS, будет применён для систематического исследования кластерообразования аминкислот в присутствии соли никеля. Основной целью при этом является определение основных направлений агломерации аминокислот и идентификация наиболее часто встречающихся кластерных ионов в масс-спектрах, проверка влияния неорганических солей на агломерацию молекул аминокислот в условиях ионизации.

\section{Эксперимент}

Для получения масс-спектров аминокислот в присутствии солей никеля использовали масс-спектрометр Bruker Maxis Impact c ионизацией в электроспрее (Bruker, Германия). Состав растворителя вода-ацетонитрил варьировали от 5 до 95\% воды. Скорость потока $-0.25 \mathrm{~cm}^{3} /$ мин, напряжение на капилляре $-4500 \mathrm{~B}$, на скиммере - 500 В. Время задержки импульса - 10 мкс. Диапазон исследуемых масс - $50-$ 300 Да. Калибровку по массам проводили с использованием раствора ацетата натрия в воде и изопропаноле (1:1). Ацетат натрия (о.с.ч., Реахим, Россия), Изопропанол 
(HPLC-grade, JT Baker, CША). В качестве модельных объектов исследования использовали набор аминокислот: аланин, пролин, тирозин, триптофан (Sigma Aldrich, США). Сухие аминокислоты растворяли в смеси ацетонитрил-вода $(1: 1)$ и получали концентрации аминокислот $10^{-5}-10^{-2} \mathrm{M}$. Хлорид никеля растворяли в смеси ацетонитрил-вода (1:1) и получали концентрации меди $10^{-6}-10^{-2} \mathrm{M}$. Все полученные концентрации смесей аминокислот и никеля указаны в таблице 1.

Таблица 1. Использованные растворы солеи и аминокислот (смешаны в соотношении 1:1 по объёму).

\begin{tabular}{|c|c|c|c|c|}
\hline $\begin{array}{c}\text { Концентрация } \\
\text { меди в растворе } \\
\text { хлорида никеля, }\end{array}$ & $10^{-5}$ & $10^{-4}$ & $10^{-3}$ & $10^{-1}$ \\
\cline { 2 - 5 } & $\mathrm{A} 1$ & $\mathrm{~A} 2$ & $\mathrm{~A} 3$ & $\mathrm{~A} 4$ \\
\hline $10^{-6}$ & Б1 & Б2 & Б3 & Б4 \\
\hline $10^{-5}$ & $\mathrm{~B} 1$ & $\mathrm{~B} 2$ & $\mathrm{~B} 3$ & $\mathrm{~B} 4$ \\
\hline $10^{-4}$ & $\Gamma 1$ & Г2 & Г3 & Г4 \\
\hline $10^{-3}$ & Д1 & Д2 & Д3 & Д4 \\
\hline $10^{-2}$ & & &
\end{tabular}

Кроме того, в работе использовали воду milli-Q, ацетонитрил JT Baker, США). Все полученные растворы были исследованы методом ESI-MS в режиме регистрации и положительных и отрицательных ионов.

\section{Обсуждение результатов}

Было показано, что появление информативных масс-спектров начинается уже с наименьшей концентрации хлорида никеля $\left(10^{-6} \mathrm{M}\right)$, с растворов A2-A-4. Наиболее представительные масс-спектры были получены для растворов А2-ГЗ. Для раствора Г4 и Д1-Д4 также получали масс-спектры, однако воспроизводимость в этих случаях была значительно хуже, часто происходило зашкаливание сигнала. В связи с этим указанные растворы исключены из рассмотрения.

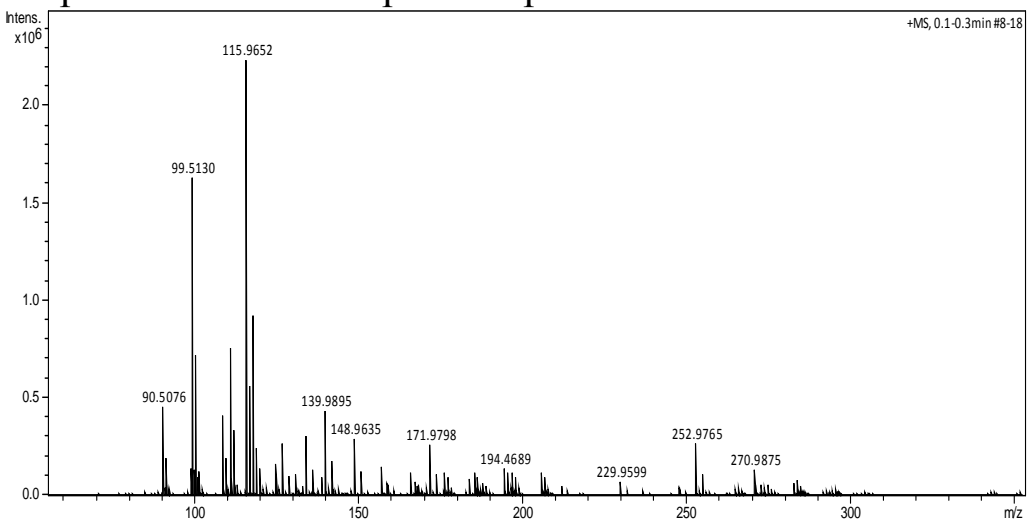

Рис. 1. Масс-спектр раствора сульфата меди с концентрацией $10^{-2} \mathrm{M}$ в режиме регистрации отрицательных ионов.

На рисунке 1 приведён масс-спектр ESI-MS раствора чистого хлорида никеля. Видно, что масс-спектр состоит в основном из никельсодержащих пиков с характерным изотопным распределением. Полученные пики трудно поддаются расшифровке. Очевидно, что пик с массой 115.9652 Да соответствует иону $\mathrm{Ni}_{2}{ }^{+}$. Кроме того очевидно, что пики 90.5076 Да и 99.5130 Да являются двухзарядными (изотопные пики имеют отличие на 1 Да, что характерно для двухзарядных никелевых кластер- 
ных ионов. Остальные ионы имеют крайне низкую интенсивность в масс-спектрах и трудно поддаются расшифровке. Разница между этими пиками соответствует отщеплению воды, ОН-группы или щелочных металлов (натрия, калия). Процесс кластерообразованния в данном случае значительно угнетён, сложных кластеров практически не образуется.

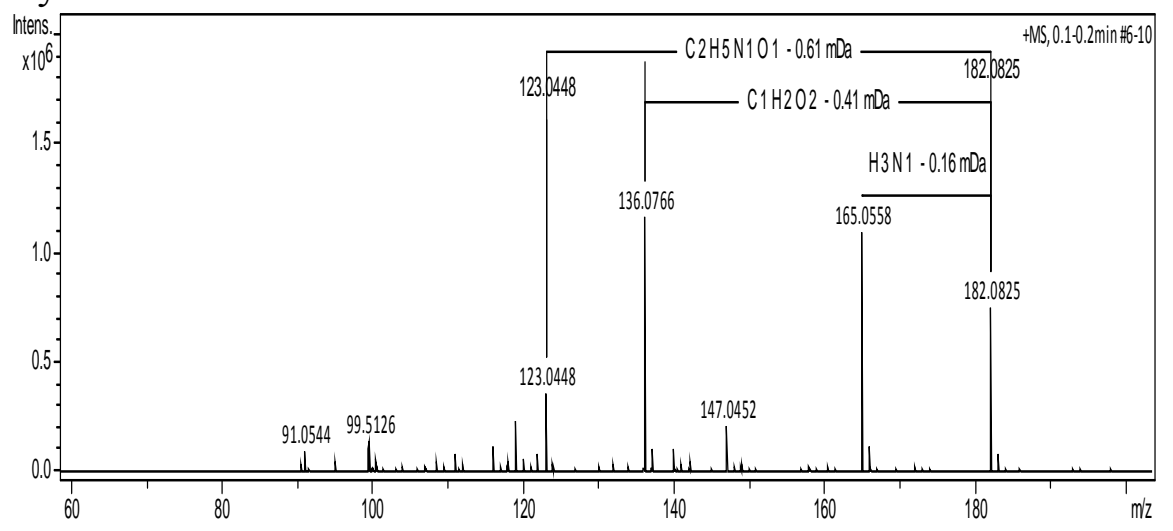

Рис. 2. Фрагмент масс-спектра раствора Г1 тирозина в режиме регистрации положительных ионов (до 200 Да).

При регистрации масс-спектров ароматических аминокислот следует отметить положительные изменения в масс-спектрах не характерные для режима регистрации аминокислот без использования солей. Так в диапазоне масс до 200 Да (рисунок 2) чётко виден не только молекулярный ион тирозина (182.0825 Да), но и его фрагментные ионы, образовавшиеся при распаде, вызванном ионизацией. Это ион 165.0558 Да (продукт потери аминогруппы), 136.0766 Да (продукт декарбоксилирования тирозина) и нехарактерный фрагмент 123.0448 Да, соответствующий потере целого фрагмента с карбоксильной группой, аминогруппой и $\alpha$-углеродом (в виде $\mathrm{H} 2 \mathrm{~N}-\mathrm{CH} 2-\mathrm{C}(\mathrm{O})-\mathrm{OH})$. Такую чёткую фрагментацию, которая подтверждает структуру целевого соединения без использования тандемной масс-спектрометрии получить без использования солей невозможно. Отдельно стоит отметить, что в масс-спектре отсутствуют мешающие ионы солей никеля (присутствуют только в низкой области до 120 Да).

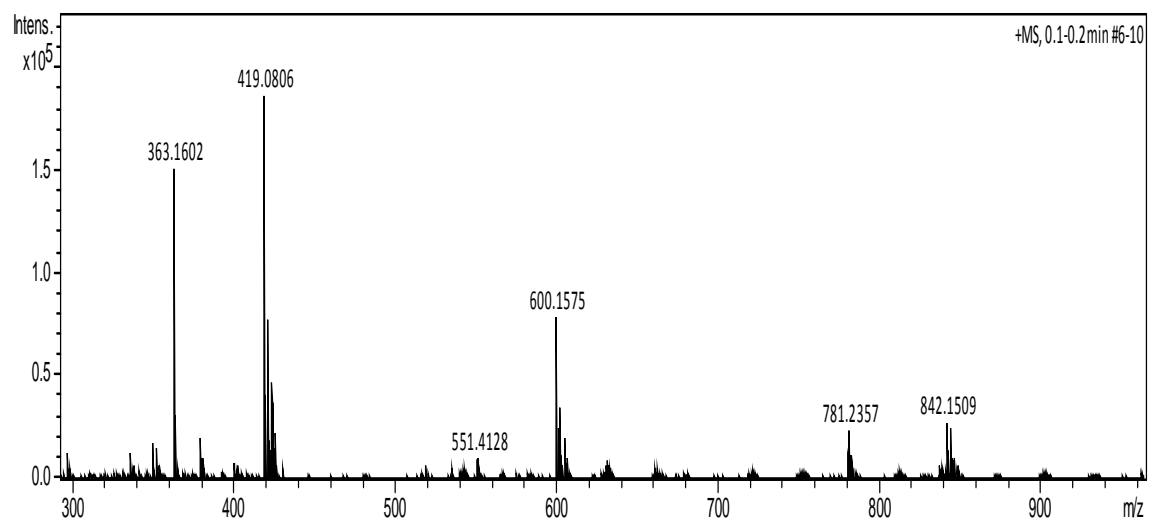

Рис. 3. Фрагмент масс-спектра раствора Г1 тирозина в режиме регистрации положительных ионов (более 300 Да).

При рассмотрении масс-спектра пролина в области более 300 Да можно обнаружить продукты взаимодействия тирозина с ионами никеля. Так на фоне заряженного димера тирозина (363.1602 Да) присутствует и продукт ионизации димер $+\mathrm{Ni}^{+}$ (419.0806 Да). При этом обнаружить тример в масс-спектре не удаётся. Однако присутствует высокоинтенсивный пик тример+ $\mathrm{Ni}^{+}$(600.1575 Да). То же можно сказать 
и о тетра мере который присутствует лишь в виде тетрамер $+\mathrm{Ni}^{+}(781.2357$ Да) и тетрамер $+2 \mathrm{Ni}_{2}{ }^{+}$(781.2357 Да).

Особо следует отметить, что кластерообразование неароматических аминокислот, например пролина, происходит в данном случае строго как и при исследовании солей меди [8], то есть идёт по трём направлениям: образование протонированных агломератов аминокислот (до трёх-четырёх молекул), образование агломератов с зарядом на ионе никеля (до четырёх-пяти молекул аминокислот) и образование двузарядных агломератов с двумя атомами никеля (начиная с димера и до пяти молекул аминокислоты).

\section{Заключение}

Проведено систематическое исследование кластерообразования аминокислот методом ESI-MS в присутствии соли никеля. Показано, что для ароматических аминокислот (тирозина, триптофана) добавление соли никеля вызывает характерную фрагментацию, которую возможно использовать для более надёжного определения целевого соединения наряду с точным значением массы. Для неароматических аминокислот выделено три направления кластерообразования. Показано что в этом случае агломерация молекул может идти вокруг трёх различных заряженных центров. В работе показано, что добавление соли никеля позволяет проводить мониторинг аминокислот без применения тандемной масс-спектрометрии за счёт прохождения фрагментации и кластерообразования в присутствии исследуемой добавки.

\section{Список литературы/References}

1. Lin L., Weng C., Chen Q., Nuclear Instruments and Methods in Physics Research Section B: Beam Interactions with Materials and Atoms, Vol. 414, No 1, pp. 79-83.

2. Kozlov A.N., Konovalov V.S. Communications in Nonlinear Science and Numerical Simulation, Vol. 51, pp. 169-179

3. Murakami K., Sato A., Hashimoto K., Fujino T., Chemical Physics, Vol. 419, pp. 3743.

4. Wieser A., Schneider L., Jung J., Schubert S., Applied microbiology and biotechnology, Vol. 93, No 3, pp. 965-974.

Кузнецова Елена Сергеевна - старший научный сотрудник лаборатории синтеза и исследования сорбентов, к.х.н. Институт физи- ческой химии и электрохимии имени А.Н. Фрумкина РАН, Москва

Пыцкий Иван Сергеевич - старший научный сотрудник лаборатории физико-химических основ хроматографии и хромато-масс-спектрометрии, к.х.н. Институт физической химии и электрохимии имени А.Н. Фрумкина РАН, Москва

Буряк Алексей Константинович - заведующий лабораторией физико-химических основ хроматографии и хромато-масс-спектрометрии, проф, д.х.н. Институт физической химии и электрохимии имени А.Н. Фрумкина РАН, Москва
5. Pytskii I.S., Petukhova G.A., Kuznetsova E.S., Khozina E.V.et al., Surface Innovations, Vol. 5, No 3, pp. 179-187.

6. Pytskii I.S., Kuznetsova E.S., Buryak A.K., Colloid Journal, Vol. 80, No 4, pp. 427-438.

7. Aggerholm T., Nanita S.C., Koch K.J., Cooks R.G., Journal of mass spectrometry, Vol. 38, No 1, pp. 87-97.

8. Kuznetsova E.S., Pytskii I.S., Buryak A.K. // Sorbtsionnye i khromatograficheskie protsessy, Vol. 18, No 5, pp. 745-750.

Kuznetsova Elena S. - PhD (chemistry), laboratory of synthesis and investigation of sorbents, Institute of Physical chemistry and electrochemistry, Moscow

Pytskii Ivan S. - PhD (chemistry), laboratory of physical-chemical basics of chromatography and chromato-mass-spectrometry, Institute of Physical chemistry and electrochemistry, Moscow. E-mail: ivanpic4586@gmail.com

Buryak Alexey K. - prof., grand PhD (chemistry), laboratory of physical-chemical basics of chromatography and chromato-mass-spectrometry Institute of Physical chemistry and electrochemistry, Moscow 